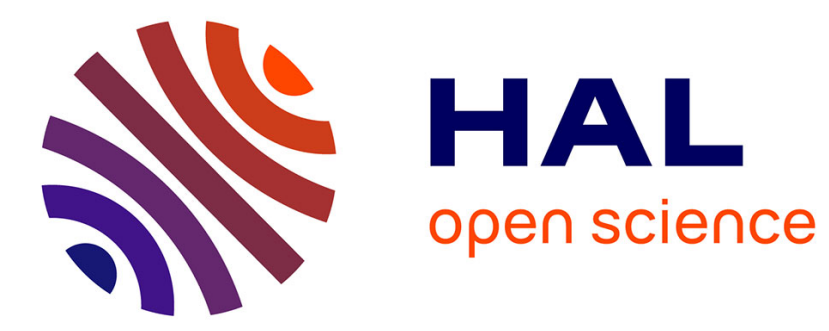

\title{
On image segmentation methods applied to glioblastoma: state of art and new trends
}

Clément Dupont, N. Betrouni, N. Reyns, M. Vermandel

\section{To cite this version:}

Clément Dupont, N. Betrouni, N. Reyns, M. Vermandel. On image segmentation methods applied to glioblastoma: state of art and new trends. Innovation and Research in BioMedical engineering, 2016, 37 (3), pp.131-143. 10.1016/j.irbm.2015.12.004 . hal-01325355

\section{HAL Id: hal-01325355 \\ https://hal.science/hal-01325355}

Submitted on 6 Jun 2016

HAL is a multi-disciplinary open access archive for the deposit and dissemination of scientific research documents, whether they are published or not. The documents may come from teaching and research institutions in France or abroad, or from public or private research centers.
L'archive ouverte pluridisciplinaire HAL, est destinée au dépôt et à la diffusion de documents scientifiques de niveau recherche, publiés ou non, émanant des établissements d'enseignement et de recherche français ou étrangers, des laboratoires publics ou privés. 


\title{
On image segmentation methods applied to glioblastoma: state of art and new trends
}

\author{
C. Dupont ${ }^{1 *}, \mathrm{PhD}$ student, N. Betrouni ${ }^{1}, \mathrm{PhD}$, \\ N. Reyns ${ }^{1,2}, \mathrm{MD}, \mathrm{PhD}, \mathrm{M}$. Vermandel $^{1,2}, \mathrm{PhD}$
${ }^{1}$ Univ. Lille, Inserm, CHU Lille, U1189 - ONCO-THAI - Image Assisted Laser Therapy for Oncology, F-59000 Lille, France
${ }^{2}$ CHU Lille, Neurosurgery Department, F-59000 Lille, France

*Corresponding author: clement.dupont@inserm.fr

\begin{abstract}
:
Because of high heterogeneity and invasiveness, treatment of GlioBlastoma Multiform (GBM) still remains a complex challenge. Several recent advanced therapies have improved precision of treatment deliverance. Multimodality imaging plays an increasingly important role in this process and images segmentation has become an essential part of the pipeline of standard treatment planning system. With the sophistication of multimodality information, the development of reliable and robust segmentation algorithms to overcome manual segmentation and optimize targeted treatment is highly expected.

In this paper, we first introduce targeted therapies applied in the GBM clinical care, from routine or research. Different segmentation methods from state of the art are highlighted to achieve GBM delineation. New trends in GBM segmentation such as machine learning and multimodal features are discussed. These additional frameworks may achieve segmentation with refining capacities, active tumour probability mapping and, even, tumour relapse prediction capacities.
\end{abstract} therapies

Keywords: segmentation,neuro-oncology, radiation oncology, high-grade glioma treatment, targeted

\section{Introduction}

Central nervous system (CNS) cancer is the 10th leading cause of death by cancer in the population over 20 years. Gliomas represent about 3\% of premature cancer death (aged less than 65) and is the 3rd cause of death by cancer for young adults (aged between 15 and 34) [1]. Among them, Glioblastoma Multiform (GBM) is the most common tumour with a very poor prognosis (median survival below 18 months). About 12,000 in the USA[2] are annually diagnosedand its incidence is estimated at 5 to 7 new cases each year for 100,000 inhabitants [3].Nowadays, the main goal of the therapy is to improve lifespan while maintaining a decent quality of life for patient bearing GBM[3].

In this context and on behalf the European Organization for Research and Treatment of Cancer-National Cancer Institute of Canada (EORTC-NCIC), Stupp et al. [4]proposed a specific treatment protocol for high grade glioma. This protocol combined 3 main therapies: surgery, radiotherapy and chemotherapy. Nowadays, this combination still remains the standard protocol in the management of GBM.

The quality of surgery is a documented prognostic factor of survival[5]. However, even in adequate removal, the invasive nature and rapid proliferation of GBM do not allow its control by conventional treatment protocols. Patients whose tumour location does not allow for tumour resection have then a limited survival.

Thus, the main issue for the treatment of GBM relies on itsvery heterogeneoustumour tissue properties (see figure 1). GBM is made of a macroscopiccomponent, the tumourbulk, and a component infiltrating 
thesurrounding tissue. Furthermore, oedemasurrounding the tumour may also be partially infiltrated with tumour cells. The differentiation between oedema, healthy tissue and tumours cells is a major issue when considering local therapy based on target definition such as radiation oncology[4], laser therapies[6], High Intensity Focused Ultrasound (HIFU)[7]. As, no segmentation approach can fit all brain tumour type, GBM segmentation results in specific strategy to manage its heterogeneous properties.
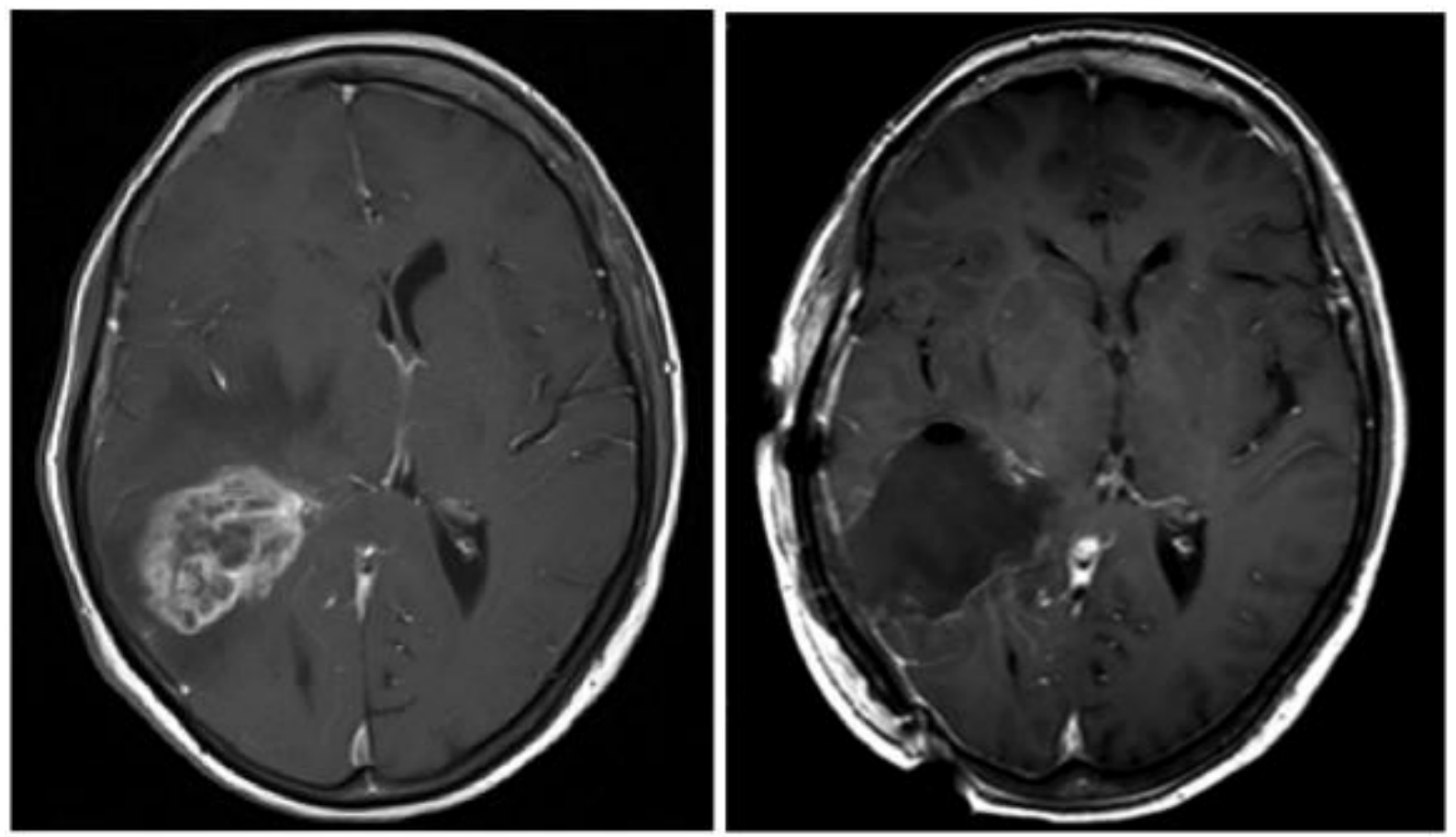

Fig. 1Pre-operative MRI showing a high-grade glioma located in associative areas and ventricular crossroad. On the right, early post-operative control $(<72 \mathrm{~h})$ with no more contrast enhancing tumour.

We propose here a review of methods developed to address the issue of GBM segmentation. First, we introduce the therapies, based on target delineation, in use to tackle GBM. Then, we present different methods of segmentation from the literature. Finally, we highlight the new trends in GBM segmentation and discuss the rational of using approaches resulting in binary segmentation while addressing infiltrating tumour.

\section{Therapies of high-grade gliomas}

\section{Standard protocol}

Depending on the GBM location, surgery is firstly achieved.It aims to achieve maximal cytoreduction without affecting the functional prognosis of patients because of their pejorative prognosis (see figure 1). After the resection of the tumour bulk, Fluorescence-Guided Resection (FGR) [8-10]can be used tooptimize the cytoreduction. FGR relies on the administration of a photosensitizer(or its precursor). FGR is mainly performed using 5-ALA which is the precursor of Protoporphyrin IX (PpIX; use in clinical practice of 5-ALA is authorized since 2007 in Europe, commercial name: Gliolan - Medac, Germany)[11]. PpIX is a photoactive compound that absorbs blue light (404 nm). PpIX is mainly fixed in the tumour cells. Indeed, Photodynamic detection offers $89 \%$ sensitivity and $96 \%$ specificity [12]. After excitation of the PpIX by a filtered violet-blue light source [13, $14]$, remainder of the tumour shines bright red through the blue surgical field.

Several studies reportedits efficacy to achievecomplete resection:about $65 \%$ of tumour tissue removed[15]. Nevertheless, temporary impairment of neurological function could occur more frequently. Those effects must be compared to the benefits and the impact on the lifespan. It was observed that the degree of surgical resection correlates approximately with the survival probability.Indeed, the progression-free clinical survival increased of about 6 months (6,73 months to 12,88 months) and clinical survival increased of about 8 months (12,3 months to 20,9 months) [16].

In addition to surgery,radiotherapy is delivered[17]. Tumourdelineation isrequired to plan the treatment. First, Gross Tumour Volume (GTV) is easily delineated from T1, T1Gd and T2 weighted. Then, Clinical Target 
Volume (CTV) is deduced from the GTV.Ballistic optimization is highly sensitive to this CTV butitsdelineation remains very complex because of the infiltrating component of the Glioma.

Chemotherapy may be also delivered, in addition to the radiotherapy. Most of studies revealed that these adjuvant treatments could not bring solutions for the recovery of a patient.However, chemical application on residual tumour cells after resection surgery can produce an effect onlifespan[18].

\section{Recent advanced therapies}

Recently,High-Intensity Focused Ultrasound (HIFU) has shown interest and significance for the managementof high-grade gliomas.HIFU is a targeted treatment based on high-intensity ultrasound $[19,20]$.This technology consistsof focusinghigh-energy ultrasounds in order to create thermal and mechanical effectson the targeted tissues. It can be delivered extracorporealy, intracavitarly and interstitially.The resulting heat and pressureincrease lead to a coagulation necrosis [21]. HIFU have been trained on different pathologies and tissues: glaucoma, pancreas,prostate, liver, thrombolysis, venous insufficiency and braintumour. A recent study demonstrated its benefit on antitumor effect paired with chemotherapy in the GBM case[7, 22].

Since 2002, a new modalityhas brought the possibility to treat non-resectable GBM using interstitial Photo-Dynamic Therapies (PDT)[23]. PDT is aselective therapy that consists in exposing photosensitized tumour cells to a specific wavelength light. Such exposition aims to generate a cytotoxic effect.Recentdevelopments offer new possibilities for the management of high-grade gliomas[24-26].

In a general manner, PDT can be delivered extracorporealy, intracavitarly orinterstitially[27]. This therapy has been trained on other localizations like prostate cancer [28, 29], lung cancer [30]or dermatology [31, 32]. PDT relies on three main parameters:

- Photosensitizer (PS): previously administered to the patient, leads to a photosensitizer, preferentially fixed in the tumour site. Several studies [23, 33-36] reported the use of a precursor,5-AminoLevulinic Acid (5-ALA). 5-ALA induced a specific uptake of the PS: the Protoporphyrin IX (PpIX). Significant difference of PS concentration between healthy and tumour tissuesled to a selective treatment.

- Light: illumination to an appropriate wavelength (corresponding to the red visible light, between 620 to $690 \mathrm{~nm}$ ) is the cornerstone that brings the required energy for the chemical reaction which ends up to production of cytotoxic molecule (singlet oxygen) [37].

- Oxygen:the tumour tissue needs to be oxygenated in order to induce cytotoxic reaction. The singlet oxygen is the most reactive product ofthe chemical reaction and will induce the deathof cells according to mainlytwo ways: necrosis and apoptosis.

A recent study introducedpreliminaryexperiments of interstitial PDT(iPDT) applied tohigh-grade gliomas [38]. In this context, optical fibers were inserted into the tumour location under stereotactic conditions.

\section{Imaging of high grade glioma}

High-grade glioma is mainly diagnosed through MRI imaging and confirmed according to histopathology analysis from biopsies or biological material from surgical excision (see figure 2). T1 weighted imaging with contrast enhancement from gadolinium (T1Gd) is acquired to observe the blood brain barrier disruption. Necrotic area can be observed by hypo intense part of the tumour core. T2-weighted (T2) or FLuid-Attenuated Inversion Recovery (FLAIR) MRI, are used to determine the extent of the tumour and of the oedema[39]. MR spectroscopy imaging (MRSI) may be used to evaluate metabolite levels measured to detect viable tumour part, especially in the tumour border or in the oedema where infiltrating tumour cells occur[40]. Tumour infiltration may also be evaluated according to diffusion-tensor MR imaging using a metric, Tumour Infiltration Index (TII) where the TII is a measure of the change in Fractional Anisotropy (FA) probably caused by tumourcells infiltrating the peritumoral oedema[41]. Vessels proliferation is an important biomarker to stage the grade of gliomas, in that context perfusion MRI remains an important tool for diagnosis and prognosis of patient harbouring high-grade glioma [42]. 
T1

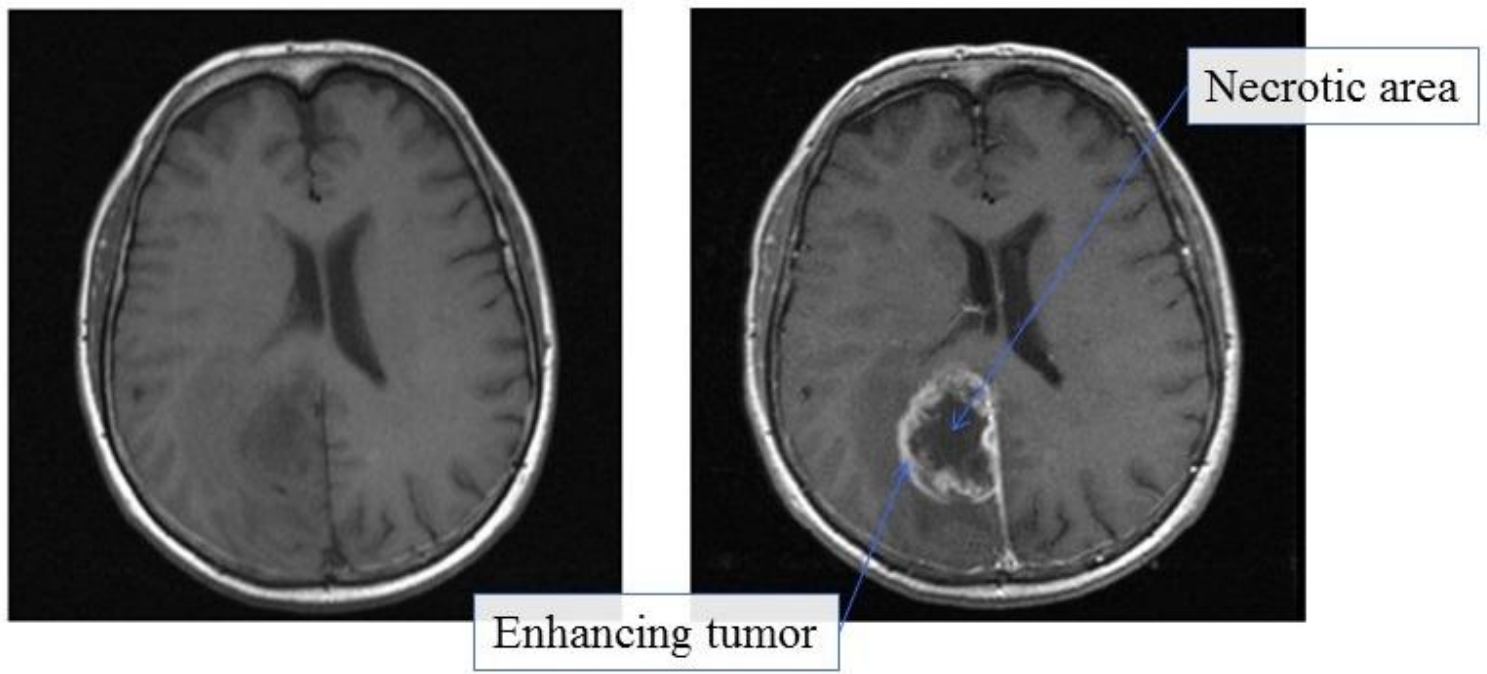

$\mathrm{T} 2$

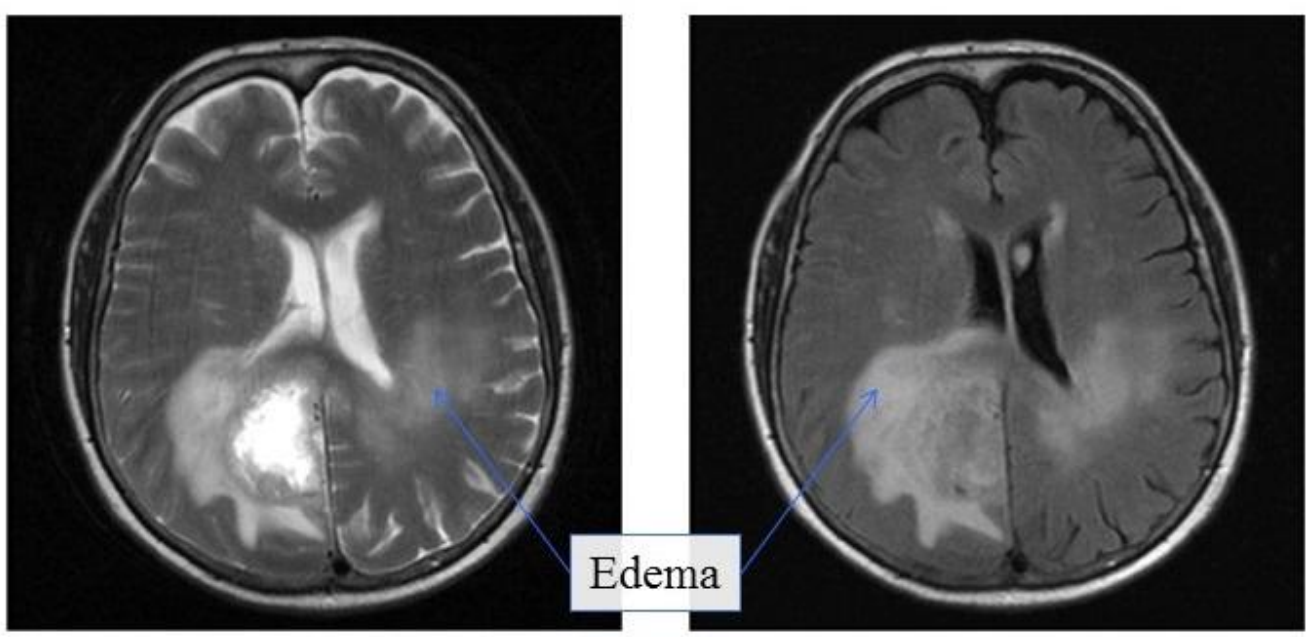

Fig. 2Illustration of four different MRI modalities of the same clinical case: T1 in the top left-hand corner, T1Gd in the top right-hand corner, T2 in the bottom left-hand corner and FLAIR in the bottom right-hand corner (DICOM files are freely available on the National Institutes of Health Blueprint for Neuroscience Research (NITRC) website). We observe a strong hypo signal on the T1Gd, which is distinctive of necrotic tissue; an intense contrast on T1Gd for the enhancing part of the tumour; a diffuse signal on T2 and FLAIR showing the extent of the tumour and the oedema.

\section{Role of the segmentation}

In most of the therapies, optimization of the treatment (Radiotherapy, PDT, HIFU, tumourresection guided by neuronavigation[43] or augmented reality[44]) requires the delineation of a target. Although it is crucial to destroytumour tissue,sparing healthy tissue is a critical issue. Indeed, patients bearing a high-grade glioma have a restraint lifespanwhich most of therapies aim to enhance whilepreserving quality of life as much as possible[45].In this context, tumour segmentation is high of interest for both optimizing the treatment delivery to the tumour and sparing healthy tissues.Furthermore, manual delineation remains unsatisfactory because of its poor inter-observers reproducibility and because it is time consuming[46].

Thus, with the sophistication of multimodalityinformation[47],development of reliable and robust segmentation algorithms to overcome manual segmentation and optimize targeted treatment is highly expected.

\section{State of the art}


In 2013, Gordillo et al. [48] has already proposed an extensive state of the art on MRI brain tumour segmentation. In this paper, we only focus on GBM segmentation.

Four main classes can be highlightedforGBM segmentation among the literature:

- Region-based approaches

- Edge-based approaches

- Classification based approaches

- Atlas-based approaches

\section{Region-based approaches}

Region-based approaches aim to provide segmentation through the finding of coherent regions or pixel similarities (see conventional pipeline on figure 3). In the context of GBM segmentation, several methods have been explored.

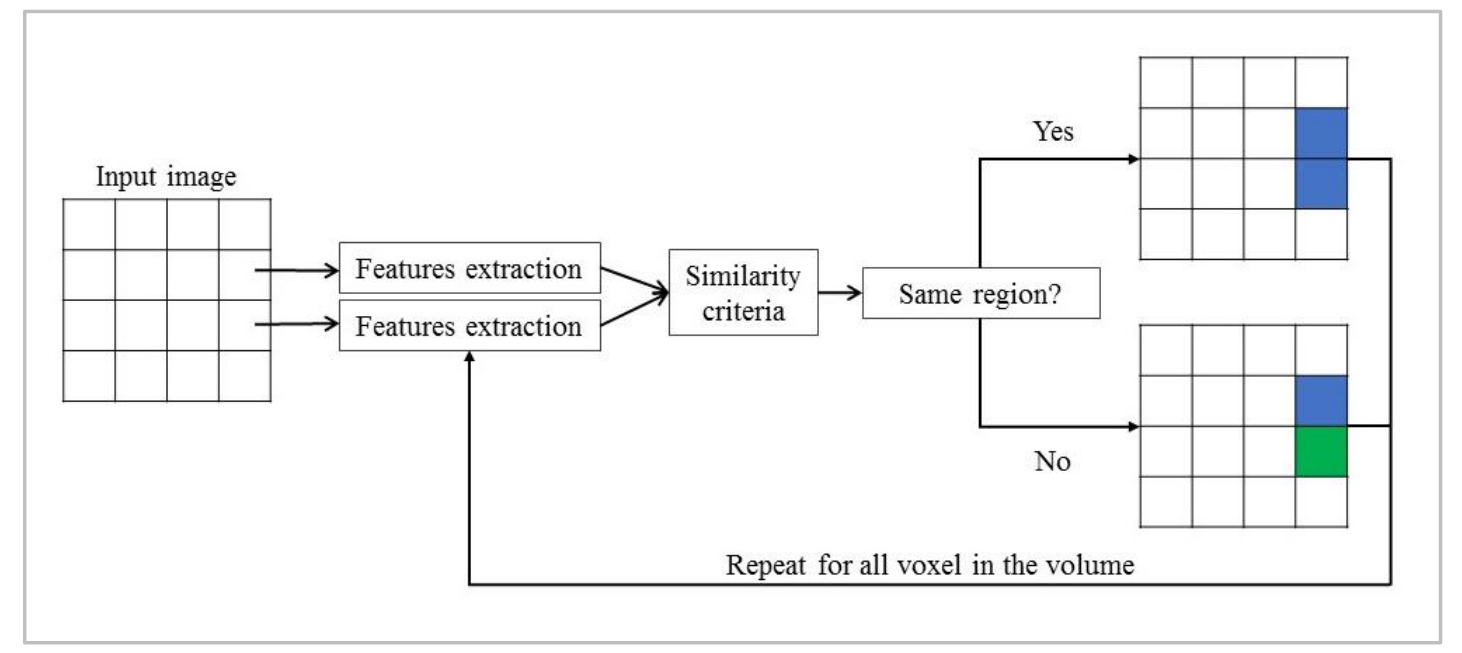

Fig. 3 Conventional pipeline of region-based approach: features of one voxel and their neighbourhoods are analysed. According to similarity criteria pre-defined, voxels are clustered.

Letterboer et al. introduced a watershed segmentation algorithm in 2004 [49] applied to tumour segmentation from MRI images. This method was mainly dedicated to preoperative neurosurgery planning. Using neuro-navigation, pre-operative segmentation of the tumour allows to the neurosurgeon a quick distinction of the resection boundaries scheduled. To overcome the well-known issue of over-segmentation when applying watershed framework, the authors introduce a multiscale analysis. Usually, merging strategies are used to obtain larger regions corresponding to the object of interest. In their paper, Letterboer et al. describe a multiscale approach aiming to define how the catchment basins merge into larger structures.For their experiments, the authors applied the algorithm on T1GdMRI images from 20 patients. Gold standard was achieved by segmentations manually performed by three physicians. To evaluate the reproducibility, automatic delineation was applied twice to each dataset. The results tended to show that the watershed was more reproducible than manual delineation. Accuracy was found equal to manual delineation. With a computational time of 10 minutes for the watershed algorithm and between 1 to 15 minutes dedicated to the operator interaction. The authors claimed that their watershed approach was three times more efficient than manual delineation.

Franz et al. presented a 3D region growing approaches in 2011 allowing distinction of the enhanced tumour part, necrotic area and perifocaloedema[50]. This algorithm used MRI T1Gd andFLAIR was dedicated to a regular clinical routine. This semi-automatic method, initialized by a starting point, or "seed",dropped by the physician, only usedimage intensity as feature. Algorithm started a previoussubsamplinganalyse of $\mathrm{T} 1 \mathrm{Gd}$ and FLAIR MRI prior to segmentation atnative resolution. Pixels with similar intensity were clustered in three sets: contrast enhancement, necrosis and oedema. Upper and lower intensity thresholds of the clusters could be definedautomatically or adapted by the user. 20 clinical cases were treated, including 15 glioblastoma and 5 meningioma cases. A computational time of ten seconds was required to achieve a whole segmentation and classification. Nevertheless, over-segmentation was declared and only monofocal tumours leaded to correct results. 
Finally, because of the intrusive nature of GBM, main drawback of region-based approaches remains over-segmentation frequently observed.

\section{Edge-based approaches}

Mainly, edge-based approaches applied in the context of GBM segmentation rely on deformable contours (see figure 4).Basically, deformable contour [51-55] area two or three-dimensionalshape (curve or surface)iteratively deformed under the influence of internal and external forces.In such a manner that boundaries fit the target volume. Internal forces tend towards to keep the shape inside the tumour boundaries while external forces pull the shape in order to increase the tumour volume segmented.Main drawbacks of this approach might be its dependence on the user initializationandthe issue encountered on tumourdiscontinuity or in presence of a weak contrast.

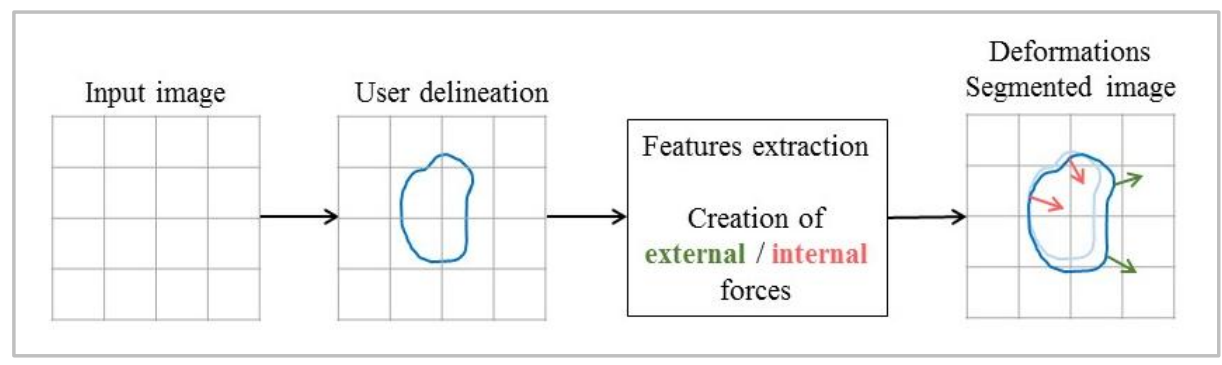

Fig. 4 Conventional pipeline of edge-based approach: a rough delineation drew by the user is used to compute forces from neighbourhood voxel of the first contour. These forces iteratively deform the initial shape under constraints to obtain the final segmentation.

In surgical and treatment planning context, Sachdeva et al. [56] described a deformable contour framework to achieve semi-automatic segmentation in 2.5 dimensions (volume extracted from 2D slices).Using intensity and texture features, this algorithm aimed to overcome weak boundaries between tumour and background and noisy sensitivity issues.MRI T1, T1Gd, T2 were used to perform this segmentation. Acharacterization map was computed by combining intensity (provided from a median filter) and texture estimations (provided from a local texture descriptor)fromtumour and non-tumour parts.From thecharacterization, anedge map was estimated to distinguish boundaries of intensity and texture estimationsfrom the tumourpart.In most of cases, this edge map did not perfectly fit the tumour contours. Thus, Static Motion Field (SMF) and Dynamic Motion Field (DMF),were achieved to guide the contour toward the tumour. This method tackled noisy images and complex tumour topologies issues.Experiments were achieved on images from 10 subjects (260 images of astrocytoma, gliomaand meningiomatumours). Time computing for a tumourranged from 2 to 5 seconds.

To improve variational segmentation framework, some authors propose to add multiple MR sequences and statistical distribution to prior knowledge. For example, Dirichlet distribution was explored by Popuri et al. [57] in order to perform a 3D segmentation. Dirichlet prior addition enables to perform a better distinction of tumour by discouraging cluster from the normal brain to move in the tumour part. After pre-processing (noise reduction, normalization and symmetry alignment), features were extracted from T1, T1Gd and T2 MRI images. Intensity and symmetry features were extracted on both $\mathrm{T} 2$ and $\mathrm{T} 1 / \mathrm{T} 1 \mathrm{Gd}$ difference. Texture feature was only extracted from T2. All these data were clustered into 3D image. A training set was weighted by including Dirichlet distribution parameters to a better distinction between tumour and the surrounding brain tissue. Finally, an automatic post-processing removed the skull and CSF of the target, delineated on each slice the tumour largest part and then, declared all pixels inside the segmented area as tumour. This method was evaluated on 15 volumes, including $11 \mathrm{GBM}$ characterized by various size, location and intensity. Senior physicians segmented manually all the volumes. Tree labels were segmented by radiologists and were used as training data set using leave-one-out cross validation. Four different metrics based on proportions between true, false, negative and positive voxels were provided for a manual segmentation comparison: Jaccard index (58\%) and distance between manual and automatic delineations (named Hausdorff distance) $(24 \mathrm{~mm})$. Time consumption was not reported.

Main drawbacks of edge-based approaches are their dependence on user's interactions and issues encountered on tumour continuity or in presence of weak contrast. However, new frameworks including multimodality and prior knowledge seem to be an interesting approach to tackle these issues.

\section{Classification approaches}


As introduced earlier, GBM imaging is usually achieved through multiple MR sequences or multiparametric MR. Thus, it makes sense to combine and exploit these data to achieve the segmentation. In this context, classification appears to be a good strategy. Classification methodsare widely used in imaging segmentation [58-61]. They aim at clustering pixels according to different features used as input vector (intensity, texture, neighboursand spatial distribution in the image) of a clustering algorithm(see figure 5). Pixels are thus represented in a multidimensional features space. Classification approaches usually referred as supervised or unsupervised.

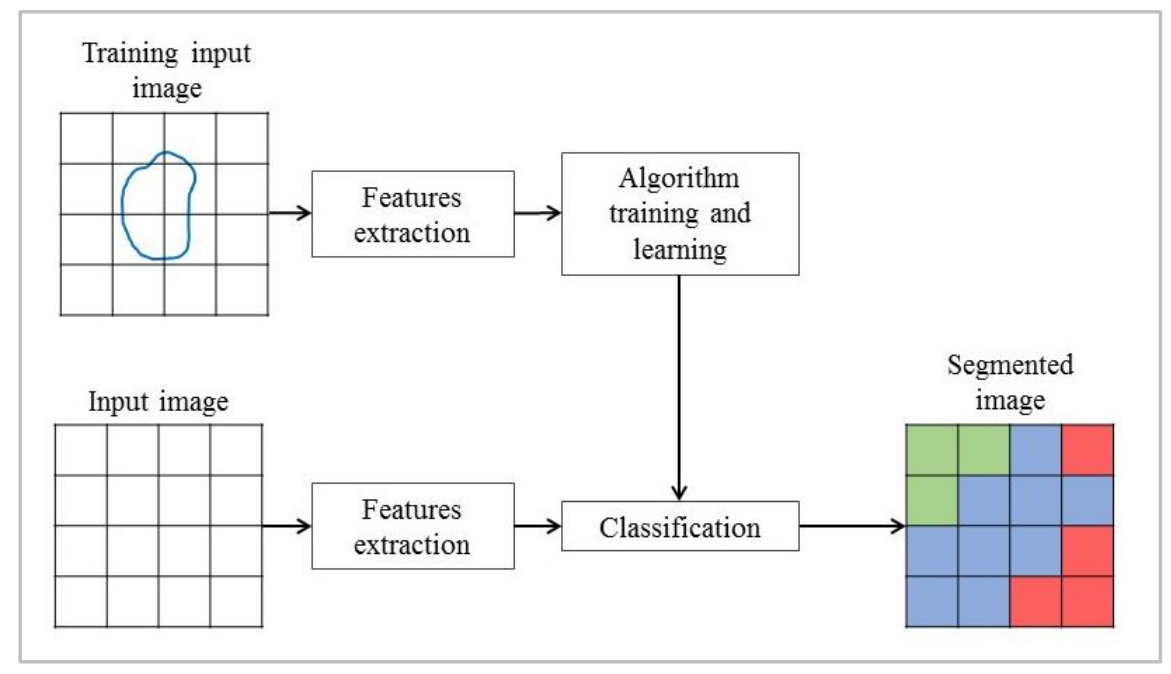

Fig. 5 Conventional pipeline of learning machine approach: in a first part, the algorithm is trained with several pre-segmented volume and learned features of voxels labelled previously. Then, the initial volume is classified according to rules learned previously by the algorithm.

A pioneer work was proposed by Clark et al. to label GBM on MRI images [62]. This study was developed to assess tumour response. Four steps composed the algorithm. First, a pre-processing algorithm classified slices as "normal" or "abnormal" using detection of morphologic deviation (symmetry of the hemispheres, CSF localization) from slices considered as "normal". Then, intra and extra-cranial tissues were discriminated: a roughly separation were performed between those two type of tissues followed by subsequent morphological operations to improve the separation. Three main tissues composed the intracranial: pathology, brain parenchyma and CSF. Using three different MRI modalities (T1, Proton Density (PD) and T2), two joint histograms were obtained: T1/PD and T2/PD to compute prior joint probability of tumour cells presence. Thus, GBM extraction could be generated by elimination of non-tumour pixels. 120 slices, including 17 for the training process were used to validate method by comparison to radiologist hand-labelled segmentation.

Corso et al. have presented a Bayesian model classification in 2008 [63].This unsupervised method was based on two concepts: class model and graph-cuts. The aim was to combine speed of graph-cuts and statistical distribution accuracy of the class model. The first one used representation of tissues heterogeneity. This distinction was achieved by a previous statistical distribution of pixels sets called Segmentation by Weighted Aggregation (SWA), developed by Sharon et al. [64] in 2001. A graph showing the similarities with neighbouring pixels was created, using features such as intensity contrast, texture difference and boundary integrity. Then, similar pixels were classified in different groups, or nodes. The notion of cuts was introduced by the fact that all these nodes were linked by an affinity and "cut" defined the threshold between two groups. The proposed method was to introduce a probabilistic Bayesian model classification in the affinities computing on the graph. Using these new affinities, segmentation was executed using hierarchy between pixels sets. This model was applied to 20 GBM cases with T1, T1Gd, T2 and FLAIR previously analysed by experts. Correlation of about $70 \%$ was obtained with comparison of expert manual delineation. The entire segmentation of a volume was computed between one and two minutes and five minutes dedicated to pre-processing.

In 2013, a semi-automatic graph-cut based method was proposed by Jiang et al. to segment brain tumours using T1, T1Gd, T2 and FLAIR MRI images [65]. This method used arithmetic operation over imaging modalities (subtraction between modalities like T1-T2 or T2-FLAIR) in order to obtain a better separation between brain tumour and background. Because of their high discrimination of tumour part in MRI images, texture properties were also extracted with the use of a Gabor filter. In addition, Real-AdaBoost algorithmdrew up a probability mapdiscriminating target from the background. Two classifiers (global and local) were trained with samples from features population set for the global classifier case and with seed points in the testing image 
for the local classifier case. A cost function containing two parts (region term and boundary term) was dressed and defined the final segmentation. During 2 hours, the global classifier treated 57 cases with 4 modalities, which represents 228 images. AdaBoost algorithm was the most time-consuming phase of the segmentation. The DSC was about $84.5 \% \pm 9.4$, Jaccard $74.1 \% \pm 14.5$, sensitivity $87.2 \% \pm 7.9$ and specificity $83.1 \% \pm 14.8$.

Fuzzy C-meansis a popular unsupervised clustering method. In 2014, Cordova et al. developed a semiautomatic tumour segmentation tool using T1 images [66] based on fuzzy c-means. In the context of FGR, this approach was used to plan surgery on preoperative images and to assess the excision on the post-operative images. Fuzzy algorithm employs only intensity variance as feature to cluster voxels. A comparison between the three clusters fuzzy algorithm, a fuzzy algorithm with four clusters and another unsupervised algorithm based on similar clustering process was dressed. 37 cases of which 16 had received FGR had been studied. Fuzzy with three classes turned out to be the most in agreement with experts' manual segmentation and also,more reproducible than the other (DICE coefficient which represents correlation with manual segmentation was about $0.943 \pm 0.018$ ). Time computing was about 3 minutes which 86 seconds used only by fuzzy algorithm.

Recently, Juan-Albarracín et al. proposed an automated classification dedicated to GBM segmentation [67]. After image pre-processing stage (denoising, skull stripping, intensity homogeneity and resolution corrections), intensity and texture features were extracted from T1, T1Gd, T2 and FLAIR MRI images. With these features, several others images were computed from arithmetical and statistical operations: absolute subtraction of T1 by T1Gd and shape of the histogram distribution (mean, skewness and peakedness). In this study, probabilities maps of white, grey matter and CSF were drawn to obtain representation biologically more relevant. These maps were computed by a comparison with a modified healthy brain atlas (the parts where tumour was located were deleted). The final segmentation was obtained by removing non-pathological tissues and discriminating pathological tissues with statistical distribution. GBM heterogeneity and infiltrative property were integrated in this segmentation approach; each tissue was modelled by a mixture of two Gaussians at least. Time reported was about 140 minutes. This technics achieved the first position of unsupervised method and the seventh of general position during the BraTS 2013 challenge (Brain Tumour Segmentation).

\section{Atlas-based approaches}

Segmentation of known healthy structures can help to extract GBM tissues. Atlas-based approaches have been investigated in that way. An atlas is a standard anatomical model in which, all internal structures and their associated properties are represented [68, 69] (see on figure 6). However, simple segmentation based on a brain atlas including GBM cannot be used due to GBM intrinsic properties. GBM location, shape, tissues heterogeneity, various volumes and impact on the brain patient topology make the creation of such an atlas tricky [70]. Nevertheless, some techniques use atlas as previous parameters in their method to optimize and/or increase complexity of their algorithm. In these statistical models [71], native images are matched to an atlas or template.

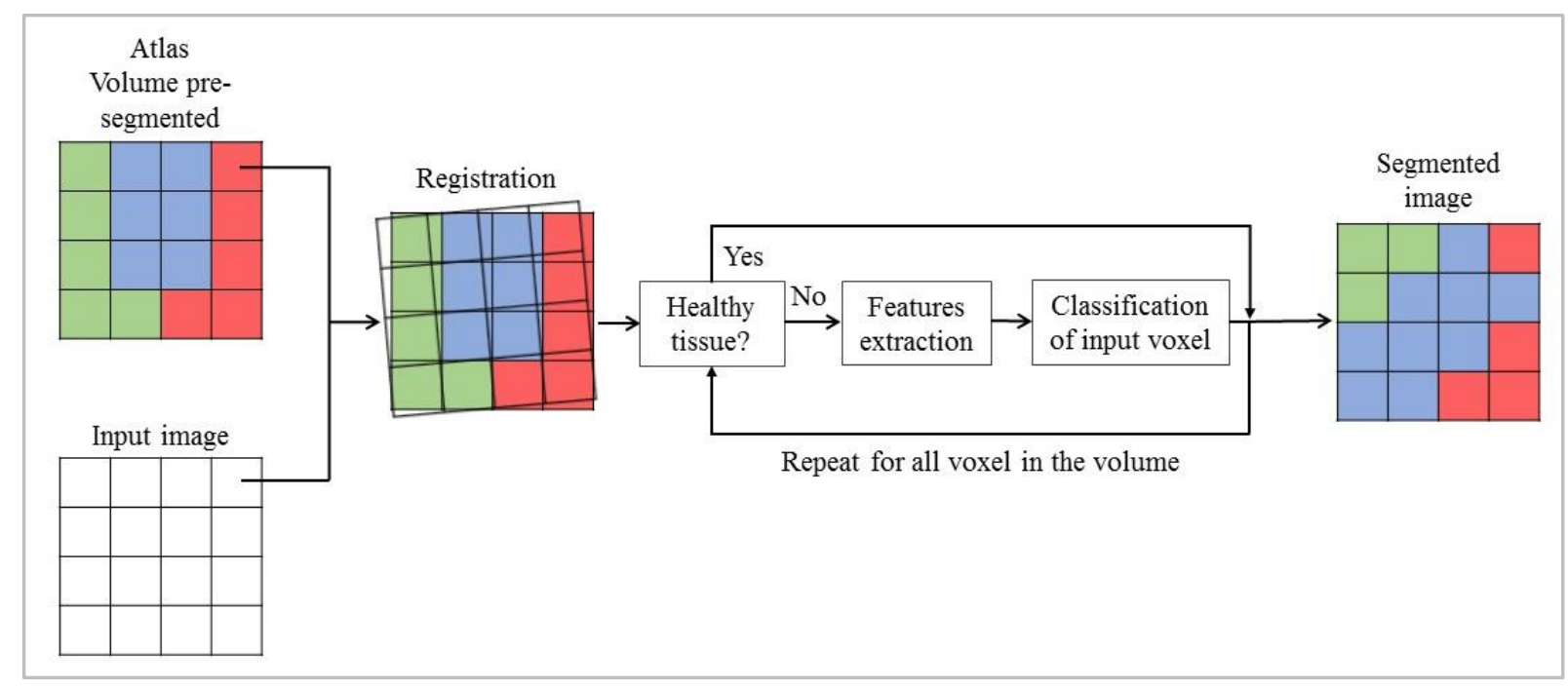


Fig. 6 Conventional pipeline of atlas-based approach: an atlas segmented previously is used to find similarities with the studied volume. Voxel are thus labelled in comparison with the atlas to obtain the final segmentation.

In this way, Prastawa et al. created an automatic brain tumour segmentation including oedema's detection [72]. This method used only T2 MRI. Pixels classification of Cerebro-Spinal Fluid (CSF), white and grey matter was performed from atlas template. Unclassified pixels were assigned to tumour or oedema. Generally, oedema was estimated as pixels located close to contrast enhancement. Finally, classification was refined from geometric and spatial properties of brain tumours. Three MRI volumes with tumours had been used to evaluate this method. Almost, 1 hour and 30 minutes were needed to process this pipeline.

MRSI enables new approaches in brain tumour segmentation. In their study, Luts et al. proposed an atlas-based segmentation built with T2 MRI images [73] and including MRSI features to characterize tumour type and grade. Known spectra and peak-integrated values of each type of gliomas tissue allowed a tumour classification (grade II, III, IV glioma and meningioma). 11 clinical cases among 24 with brain tumour, including 3 GBM cases with severely brain deformation, were used to perform this study. The addition of MRSI information brought a new approach in classification of abnormal tissues and improved the visualization of high heterogeneity GBM.

To overcome the tumour mass-effect on the brain patient, Gooya et al. proposed an atlas-based segmentation with an increased complexity in their prior atlas [74]. A glioma growth model (unknown grade) was implanted in a healthy atlas brain. Tumour, oedema and grey matter probability maps were generated using diffusion-reaction equation. Mass effect strength displacement, proliferation coefficient and spatial position were taken in consideration. Then, a joint segmentation-registration was applied on this atlas. Intensity distribution of each structure, atlas coefficient and deformation between the atlas and the reference model were estimated to complete this pipeline. 10 clinical cases of glioma imaged by T1, T1Gd, T2 and FLAIR were used. This model showed a mean difference of the dice overlap with previous expert manual delineation of less than $0.75 \%$. The registration between modified atlas and the segmented patient images closely matched which demonstrated a good simulation of glioma growth.

Atlas-based approach represents an interesting way to classify the type of tissues in the volume. However, creation of an atlas infiltrated by a GBM cannot be relevant due to the highly multiform morphology of GBM.

\section{New trends}

\section{Machine Learning}

As observed in the state of the art, classification and multimodality approaches are the most appropriate way to achieve GBM segmentation. Thus, finding the best combination of features over all the modalities available and the best classification becomes today a hot topic.Machine learning methodologies are progressively becoming a standard of segmentation since they are suitable for multimodality data, can include prior knowledge and their segmentation methodologies can continuously be updated from newer database.

Machine Learning methods appear in various fields with many different aspects such as linear and probabilistic models, kernel learning or clustering analysis[75-79]. These methods rely on learning processes. During learning phase, the algorithm is fed with training data for which the segmentation is known such as manual delineation from experts. For instance, this learning phase enables to tune the parameters of an artificial neural network. Obviously, the more trained is the machine learning, the more accurate will be the final segmentation.

Preliminary works on machine learning dedicated to brain tumours segmentation was achieved in 2009. Iftekharuddin et al. developed a segmentation and classification tool dedicated to paediatric brain tumours[80]. Their study used intensity and texture features computed from fractal-based algorithms (fractal dimension and fractal wavelet). Then, a map was labelled according to these three features. The Self-Organizing Maps (SOM) neural network clustered these inputs vectors into space data. After this update, classification discriminated tumour from non-tumour regions by computing the mean of the three features of each vector. Thus, the classifier indicated the location of high probability of tumour cells presence. This method was tested on 9 datasets (MRI T1, T2 and FLAIR) of patients with brain tumours, including two cases of GBM. Half of data was used as training set. The results showed a mean of $90 \%$ of true tumour tissues classified like tumour tissue. The author indicated a time computing of about $30 \mathrm{~min}$ to train the classifier for a single patient. 
Forest classifier [81, 82] was studied by Zikic et al. [83] to automatically segment GBM on multichannel MRI images. This study was focused on GBM segmentation for radiotherapy and surgery purpose. Six different MRI sequences were used: T1, T1Gd, T2 turbo spin echo (T2-tse), FLAIR and two sequences diffusion tensor imaging (DTI). During training stage, the random forest algorithm created a set of binary decisions called tree. Each tree was composed of a node, which split training samples based on their feature representation. Random number of outputs of the node was generated according to dimension space feature considered. Tree growing stopped at predefined limit and formed a forest. During the testing stage, each part of image was sent in the decision forest. A generative model of tissue (active cells, necrotic core, oedema and background probabilities) was combining with forest input in order to classify each entrance in a class tissue. This approach was tested on 40 high-grade gliomas of which 38 GBM cases. Manual segmentation of active cells, necrotic core and oedema part were drawn on the 40 patients. Tree process of cross-validation was applied: 10/30, 20/20 and $30 / 10$ corresponding of the ratio training/testing process. Training part ranged from 10 to 25 minutes and testing part, between 2 to 3 minutes. This method was tested on the 2014 BraTS challenge [84] and obtained the best results.

Support Vector Machine (SVM)[85-88], has been investigated in a recent 2D multimodal GBM segmentation approach by $\mathrm{Wu}$ et al. [89].SVM algorithm is used to solve vectors separation problem by determining the optimal mathematical solution. In addition to SVM learning process, the study introduced the notion of superpixel[90-92]. This feature, defined as group of pixels describing coarse image structure, reduced computational time, allowed a more efficiency representation with Support Vector and leaded to a more homogenous segmentation. The training data was a 4D image, composed of superpixels and containing vector value from T1, T1Gd, T2 and FLAIR.Features extracted from these vectors were the mean intensity value of each superpixel. These results were used to train the SVM classifier. Two parts composed the training process: first, the SVM was train on random negative samples and evaluate on non-tumour data. Thus, all positives were false positives. These false positives were injected in the previous negative data and used to train SVM again. Regarding to the testing data, the same process was applied to transform images with superpixels. SVM algorithm classified superpixels of the testing data. The results were sent to a Conditional Random Field (CRF) in order to regenerate pixels features from the superpixels and complete the segmentation. A last step of denoising process was applied to remove false positives. This method was experimented on 20 GBM cases with manual expert delineation. A comparison with other method (BratTs challenge, 2012) was dressed, especially with the Zikic et al. study [83], which brought better results. Time computing was about 30 min and training part was about one and a half hours.

\section{New strategies}

Progressively, it has appeared that classifying pixels as tumour or non-tumour cannot fit properly the complex structure of GBM. Thus, new strategies are applied to delineate different tumourcompartments[93](enhancing, non-enhancing tumour part, necrosis, oedema) or to map probabilities of active tumours cells(see figure 7). 


\section{T1Gd}

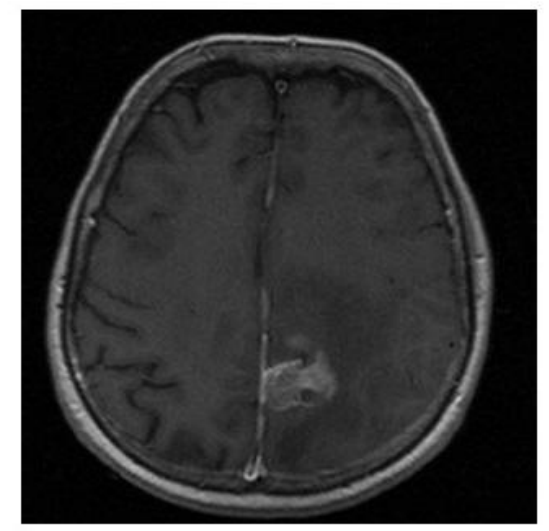

T1Gd segmented

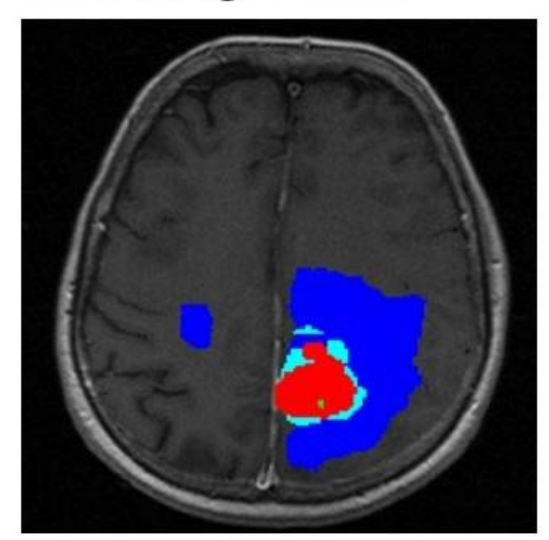

$\mathrm{T} 2$

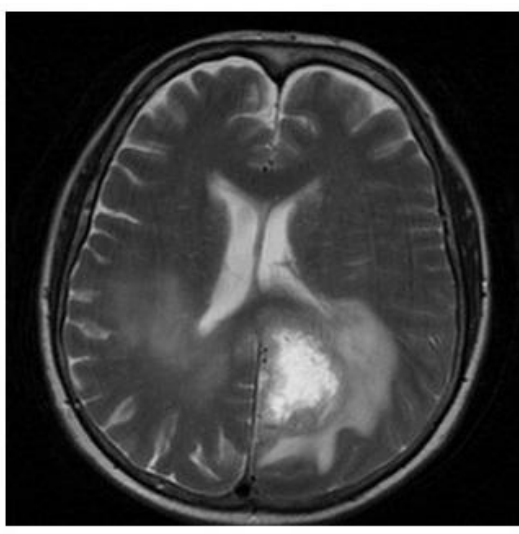

T2 segmented

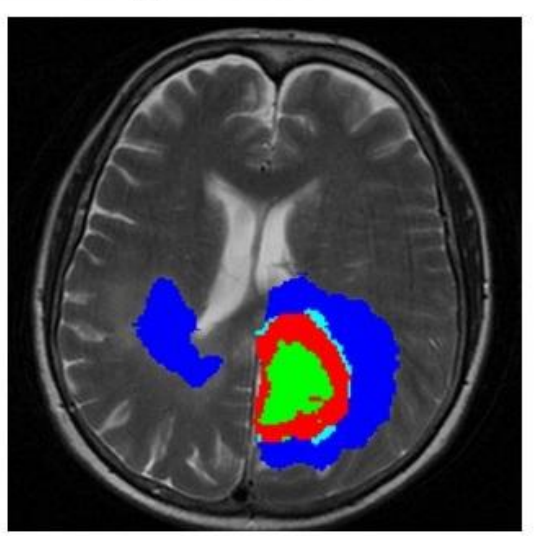

Edema

Non enhancing

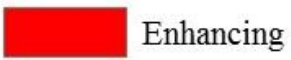

Necrotic

Fig. 7 Automatic GBM segmentation generated with the software BraTumIA (Brain Tumor Image Analysis)[94]. It requires T1, T1Gd, T2 and FLAIR to perform a whole segmentation of the necrotic part, nonenhancing, enhancing tumour andoedemain less than 5 minutes. Segmentation method used is based on a decision forest classifier.

In a recent study $[95,96]$, Unkelbach et al. developed a method based on Fisher-Kolmogorov model to describe the anisotropic GBM growth. This segmentation was included in a radiotherapy planning in order to delineate a target volume. T1, T1Gd,T2 and FLAIR were used to simulate the process. Firstly, segmentation of tumour, cerebrospinal fluid, peritumoral oedema, white and grey matter was computed using Menze et al. algorithm [97], an unsupervised statistical method. Then, the Fisher-Kolmogorov equation, which mathematically represents the diffusion behaviour for tumours cells, was employed for modelling GBM growth from two parameters: Infiltration length and the ratio diffusion coefficient in white/grey matter. One main issue stemmed from the tumour cells density, which was unknown on images. Approximations were carried out in order to circumvent this difficulty. Combining these two properties, map of simulated tumour cell density were generated.

In the same way, Hamamci et al. [98] proposed tumour segmentation, for radiosurgery purpose, based on T1Gd. The author described a tumour probability map obtained from "Cellular Automata" (CA) method. From a region of interest, CA algorithm was applied successively to foreground and background. Thus, two maps representing tumour and background strengths were provided. Fusion of these maps resulted in a tumour probability map. Finally, a probability threshold (above 0.5 ) delineated the tumour. Additionally, necrotic tissues were taken into account thanks to their hyposignal on T1Gd images. This method was evaluated on three different data sets: Five synthetic brain tumour data sets from the University of Utah [99], ten tumours including manual segmentation of Harvard experts [100] and nineteen tumours of fourteen patients from Anadolu Medical Center (AMC), Turkey. An average Dice overlap was given to compare this method to previous validated segmentation: $82,6 \pm 17,3$ for the five tumours of Utah, $89,3 \pm 6,9$ for the ten tumours of Harvard and 80,1 $\pm 6,9$ 
for the nineteen tumours form AMC. Computation time ranged from 1 second to 16 minutes depending on the tumour volume $(0,5$ to $32 \mathrm{cc})$.

Additionally, tumoursrelapse prediction is also challenging[101]. This topic is really high of interest, mostly to predict treatment response or to adapt in real time the therapy during surgical procedures.

GBM prediction model using genomic analysis as new features has been recently proposed[102-106]. Tumour invasion, growth or recurrence location may be predicted and improve targeted therapy [107-110]. In these methods, conventional imaging is completed by additional molecular mapping and able to predict patient survival prognosis. Indeed, addition of multimodality imaging is continuously proposed to optimize the predictability of tumour relapse, in particular with the use of new Positron Emission Tomography(PET) tracers [111-114].

\begin{tabular}{|c|c|c|c|c|c|c|c|c|}
\hline Author & Approach & $\begin{array}{c}\text { Advant } \\
\text { ages }\end{array}$ & $\begin{array}{c}\text { Drawbac } \\
\text { ks }\end{array}$ & Modalities & Dataset & $\begin{array}{l}\text { Computa } \\
\text { tion time }\end{array}$ & $\begin{array}{c}\text { User's } \\
\text { interactio } \\
n\end{array}$ & Therapy \\
\hline $\begin{array}{c}\text { Letterboe } \\
\text { r et al. } \\
\text { [49] }\end{array}$ & $\begin{array}{c}\text { Morphologi } \\
\text { cal filter } \\
\text { operations } \\
\text { (watershed } \\
\text { algorithm) }\end{array}$ & $\begin{array}{l}\text { Reprodu } \\
\text { cible, } \\
\text { repeatab } \\
\text { le and } \\
\text { accurate }\end{array}$ & & MRI & $\begin{array}{l}20 \text { clinical } \\
\text { cases }\end{array}$ & $\begin{array}{c}10+1-15 \\
\min \end{array}$ & $\begin{array}{c}\text { Initialized } \\
\text { manually }\end{array}$ & \\
\hline $\begin{array}{c}\text { Franz et } \\
\text { al. }[50]\end{array}$ & $\begin{array}{l}\text { Region } \\
\text { growing }\end{array}$ & $\begin{array}{c}\text { Fast and } \\
\text { robust }\end{array}$ & $\begin{array}{c}\text { User- } \\
\text { dependent } \\
, \\
\text { monofoca } \\
1 \text { tumours } \\
\text { only, } \\
\text { over- } \\
\text { segmentat } \\
\text { ion } \\
\end{array}$ & $\begin{array}{l}\text { T1Gd and } \\
\text { FLAIR }\end{array}$ & $\begin{array}{l}20 \text { clinical } \\
\text { cases }\end{array}$ & $10 \mathrm{~s}$ & $\begin{array}{c}\text { Initialized } \\
\text { manually }\end{array}$ & $\begin{array}{l}\text { Regular } \\
\text { clinical } \\
\text { routine }\end{array}$ \\
\hline $\begin{array}{l}\text { Sachdeva } \\
\text { et al. [56] }\end{array}$ & $\begin{array}{l}\text { Contour } \\
\text { (Content- } \\
\text { Based } \\
\text { Active } \\
\text { Contour) }\end{array}$ & $\begin{array}{c}\text { Comple } \\
\text { x } \\
\text { topology } \\
\text { tumours, } \\
\text { Noisy } \\
\text { insensiti } \\
\text { ve }\end{array}$ & $\begin{array}{c}2.5 \\
\text { dimension }\end{array}$ & $\mathrm{T} 1, \mathrm{~T} 2$ & $\begin{array}{l}10 \text { clinical } \\
\text { cases }\end{array}$ & $2 s-5 s$ & $\begin{array}{c}\text { Initialized } \\
\text { manually }\end{array}$ & $\begin{array}{l}\text { Surgical } \\
\text { and } \\
\text { treatment } \\
\text { planning }\end{array}$ \\
\hline $\begin{array}{c}\text { Popuri et } \\
\text { al. [57] }\end{array}$ & $\begin{array}{c}\text { Edge-based } \\
\text { with } \\
\text { Dirichlet } \\
\text { feature }\end{array}$ & $\begin{array}{l}\text { Better } \\
\text { results } \\
\text { than } 4 \\
\text { segment } \\
\text { ation } \\
\text { methods }\end{array}$ & & $\begin{array}{c}\mathrm{T} 1, \mathrm{~T} 1 \mathrm{Gd}, \\
\mathrm{T} 2\end{array}$ & $\begin{array}{l}15 \mathrm{MRI} \\
\text { volumes }\end{array}$ & & $\begin{array}{l}\text { Automati } \\
\text { c but } \\
\text { required a } \\
\text { prior } \\
\text { manual } \\
\text { segmentat } \\
\text { ion }\end{array}$ & \\
\hline $\begin{array}{c}\text { Clark et } \\
\text { al. [62] }\end{array}$ & $\begin{array}{l}\text { Knowledge- } \\
\text { based } \\
\text { segmentati } \\
\text { on }\end{array}$ & & $\begin{array}{l}\text { High } \\
\text { number of } \\
\text { "false } \\
\text { positive" }\end{array}$ & $\begin{array}{c}\mathrm{T} 1, \mathrm{~T} 1 \mathrm{Gd}, \\
\mathrm{T} 2\end{array}$ & $\begin{array}{c}7 \text { clinical } \\
\text { cases }+ \\
\text { radiologis } \\
\mathrm{t}\end{array}$ & & & $\begin{array}{l}\text { Tested on } \\
\text { patient } \\
\text { images } \\
\text { with } \\
\text { surgery, } \\
\text { radio, } \\
\text { chemothe } \\
\text { rapy }\end{array}$ \\
\hline $\begin{array}{l}\text { Corso et } \\
\text { al. [115] }\end{array}$ & $\begin{array}{c}\text { Bayesian } \\
\text { model }\end{array}$ & $\begin{array}{c}\text { Differen } \\
\text { tiation }\end{array}$ & $\begin{array}{c}\text { Non- } \\
\text { specific }\end{array}$ & $\begin{array}{c}\text { T1 T1Gd, } \\
\text { T2, }\end{array}$ & $\begin{array}{c}20 \text { clinical } \\
\text { cases }\end{array}$ & $1-2 \min$ & $\begin{array}{c}\text { Automati } \\
\mathrm{c}\end{array}$ & \\
\hline
\end{tabular}




\begin{tabular}{|c|c|c|c|c|c|c|c|c|}
\hline & & $\begin{array}{c}\text { between } \\
\text { oedema } \\
\text { and } \\
\text { brain } \\
\text { tumour }\end{array}$ & $\begin{array}{l}\text { detection } \\
\text { of GBM }\end{array}$ & FLAIR & & & & \\
\hline $\begin{array}{c}\text { Jiang et } \\
\text { al. [65] }\end{array}$ & $\begin{array}{c}\text { Learning } \\
\text { classificatio } \\
\mathrm{n}\end{array}$ & $\begin{array}{c}\text { Reliable } \\
\text { and } \\
\text { robust }\end{array}$ & $\begin{array}{c}\text { Time } \\
\text { computin } \\
\text { g can } \\
\text { increased }\end{array}$ & $\begin{array}{l}\text { T1 T1Gd, } \\
\text { T2, } \\
\text { FLAIR }\end{array}$ & $\begin{array}{l}23 \text { clinical } \\
\text { cases }\end{array}$ & $5 \mathrm{~min}$ & $\begin{array}{c}\text { Automati } \\
\text { c }\end{array}$ & \\
\hline $\begin{array}{c}\text { Cordova } \\
\text { et al. } \\
\text { [66] }\end{array}$ & $\begin{array}{c}\text { Classificatio } \\
\text { n (Fuzzy C- } \\
\text { means) }\end{array}$ & $\begin{array}{c}\text { High } \\
\text { agreeme } \\
\text { nt with } \\
\text { manual } \\
\text { segment } \\
\text { ation } \\
\text { Reprodu } \\
\text { cible }\end{array}$ & $\begin{array}{c}\text { Neoplasti } \\
\text { c tissues } \\
\text { and high } \\
\text { intensity } \\
\text { noise can } \\
\text { be } \\
\text { misclassif } \\
\text { ied }\end{array}$ & $\mathrm{T} 1$ & $\begin{array}{c}37 \text { Pre and } \\
\text { postoperat } \\
\text { ive which } \\
16 \text { FGR }\end{array}$ & $\begin{array}{c}3 \text { min } \\
\text { including } \\
\text { previous } \\
\text { segmentat } \\
\text { ion }\end{array}$ & $\begin{array}{l}\text { Unsupervi } \\
\text { sed } \\
\text { (required } \\
\text { previous } \\
\text { segmentat } \\
\text { ion) }\end{array}$ & $\begin{array}{l}\text { Pre and } \\
\text { postoperat } \\
\text { ive GBM }\end{array}$ \\
\hline $\begin{array}{c}\text { Juan- } \\
\text { Albarrací } \\
\text { n et al. } \\
{[67]} \\
\end{array}$ & $\begin{array}{c}\text { Classificatio } \\
\mathrm{n}\end{array}$ & $\begin{array}{c}\text { Specific } \\
\text { feature } \\
\text { extractio } \\
n \\
\end{array}$ & $\begin{array}{c}\text { Sensitive } \\
\text { to } \\
\text { heterogen } \\
\text { eities } \\
\end{array}$ & $\begin{array}{l}\text { T1 T1Gd, } \\
\text { T2, } \\
\text { FLAIR }\end{array}$ & $\begin{array}{c}\text { BRATS } \\
2013 \\
\text { competiti } \\
\text { on } \\
\end{array}$ & $140 \mathrm{~min}$ & $\begin{array}{c}\text { Automati } \\
\mathrm{c}\end{array}$ & \\
\hline $\begin{array}{l}\text { Prastawa } \\
\text { et al. [72] }\end{array}$ & Atlas based & $\begin{array}{c}\text { Detectio } \\
\mathrm{n} \text { of } \\
\text { oedema }\end{array}$ & & $\mathrm{T} 1, \mathrm{~T} 2$ & 3 data sets & 1h 30 & $\begin{array}{c}\text { Automati } \\
\text { c }\end{array}$ & \\
\hline $\begin{array}{l}\text { Luts et } \\
\text { al. [73] }\end{array}$ & $\begin{array}{l}\text { MRSI } \\
\text { pattern } \\
\text { recognition }\end{array}$ & $\begin{array}{c}\text { Distincti } \\
\text { on } \\
\text { improve } \\
\text { d, cyst } \\
\text { detectio } \\
n\end{array}$ & & $\begin{array}{c}\text { MRI \& } \\
\text { MRSI }\end{array}$ & $\begin{array}{c}11 \\
\text { patients } \\
\text { which } 3 \\
\text { GBM }\end{array}$ & & $\begin{array}{c}\text { Automati } \\
\text { c }\end{array}$ & \\
\hline $\begin{array}{c}\text { Gooya et } \\
\text { al. [74] }\end{array}$ & Atlas based & $\begin{array}{l}\text { Glioma } \\
\text { growth } \\
\text { model }\end{array}$ & $\begin{array}{l}\text { Simulated } \\
\text { glioma } \\
\text { grade } \\
\text { unknown }\end{array}$ & $\begin{array}{c}\text { T1, T1Gd, } \\
\text { T2, } \\
\text { FLAIR }\end{array}$ & $\begin{array}{l}10 \text { clinical } \\
\text { cases }\end{array}$ & & $\begin{array}{c}\text { Automati } \\
\text { c }\end{array}$ & \\
\hline $\begin{array}{c}\text { Iftekharu } \\
\text { ddin et } \\
\text { al. }[80]\end{array}$ & $\begin{array}{l}\text { Machine } \\
\text { Learning } \\
\text { with fractal } \\
\text { feature }\end{array}$ & & $\begin{array}{c}\text { Only } \\
\text { clearly } \\
\text { visible } \\
\text { tumour } \\
\text { considere } \\
\text { d }\end{array}$ & $\begin{array}{l}\text { T1, T2, } \\
\text { FLAIR }\end{array}$ & $\begin{array}{c}9 \text { clinical } \\
\text { cases }(204 \\
\text { brain } \\
\text { images })\end{array}$ & $30 \mathrm{~min}$ & $\begin{array}{c}\text { Automati } \\
\text { c }\end{array}$ & $\begin{array}{l}\text { Paediatric } \\
\text { brain } \\
\text { tumour } \\
\text { segmentat } \\
\text { ion }\end{array}$ \\
\hline $\begin{array}{c}\text { Zikic et } \\
\text { al. [83] }\end{array}$ & $\begin{array}{l}\text { Random } \\
\text { forest } \\
\text { classifier }\end{array}$ & $\begin{array}{c}\text { Distincti } \\
\text { on } \\
\text { between } \\
\text { necrotic } \\
\text { core, } \\
\text { active } \\
\text { cells and } \\
\text { oedema }\end{array}$ & & $\begin{array}{c}\text { T1T1Gd, } \\
\text { T2, } \\
\text { FLAIR } \\
\text { and two } \\
\text { DTI } \\
\text { channels }\end{array}$ & $\begin{array}{l}40 \text { High } \\
\text { grade } \\
\text { gliomas } \\
\text { including } \\
38 \text { GBM }\end{array}$ & $\begin{array}{l}\text { Training: } \\
\text { 10-25min } \\
\text { Testing: } \\
\text { 2-3min }\end{array}$ & $\begin{array}{c}\text { Automati } \\
\text { c }\end{array}$ & $\begin{array}{l}\text { Radiother } \\
\text { apy and } \\
\text { surgery } \\
\text { planning }\end{array}$ \\
\hline $\begin{array}{c}\text { Wu et al. } \\
\text { [89] }\end{array}$ & $\begin{array}{c}\text { SVM \& } \\
\text { CRF }\end{array}$ & $\begin{array}{l}\text { Superpix } \\
\text { el (less } \\
\text { time } \\
\text { consumi } \\
\text { ng for } \\
\text { training } \\
\text { part) } \\
\end{array}$ & $\begin{array}{c}\text { Only 2D } \\
\text { superpixel } \\
\text { s }\end{array}$ & $\begin{array}{l}\text { T1 T1Gd, } \\
\text { T2, } \\
\text { FLAIR }\end{array}$ & 20 GBM & $\begin{array}{l}\text { Training: } \\
\text { 1h30 } \\
\text { Testing: } \\
\text { 30min }\end{array}$ & $\begin{array}{c}\text { Automati } \\
\text { c }\end{array}$ & \\
\hline Unkelbac & Statistical & Tumour & Dependen & T1 T1Gd, & $10 \mathrm{GBM}$ & & Automati & Radiothera \\
\hline
\end{tabular}




\begin{tabular}{|c|c|c|c|c|c|c|c|c|}
\hline $\begin{array}{c}\text { h et al. } \\
\text { [96] }\end{array}$ & $\begin{array}{c}\text { feature and } \\
\text { growth } \\
\text { simulation }\end{array}$ & $\begin{array}{c}\text { cell } \\
\text { density }\end{array}$ & $\begin{array}{c}\text { ce to the } \\
\text { correct } \\
\text { definition } \\
\text { of } \\
\text { boundarie } \\
\text { s }\end{array}$ & $\begin{array}{c}\text { T2, } \\
\text { FLAIR }\end{array}$ & py & planning \\
\hline $\begin{array}{c}\text { Hamamci } \\
\text { et al. [98] }\end{array}$ & $\begin{array}{c}\text { Biological } \\
\text { diffusion } \\
\text { model }\end{array}$ & $\begin{array}{c}\text { Tumour } \\
\text { probabili } \\
\text { ty map }\end{array}$ & $\begin{array}{c}\text { User } \\
\text { interactio } \\
\text { nor each } \\
\text { metastasis }\end{array}$ & T1Gd & $\begin{array}{c}34 \text { clinical } \\
\text { cases } \\
\text { (with 3 } \\
\text { GBM) }\end{array}$ & minutes & $\begin{array}{c}\text { Initialized } \\
\text { manually }\end{array}$ & $\begin{array}{c}\text { Radiosurge } \\
\text { ry planning }\end{array}$ \\
\hline
\end{tabular}

Table 1summary of the segmentation approaches: advantages and drawbacks, evaluation and modalities used, computation time, user-interaction level and therapeutic modality. 


\section{Discussion-Conclusion}

Gliomas are the most common primary brain tumour and GBM its most aggressive form. Nowadays, conventional treatments fail to cure it. To improve its management, new health technologies may be applied (HIFU, Laser therapies) relying on an accurate definition of the target. We proposed a general review on segmentation technics: region-based, edge-based, atlas-based and classification approaches. These usual approaches are summarizedin table 1 .

However, beyond usual segmentation frameworks, we have also highlighted new trends. First, multimodal strategies should clearly be added to segmentation frameworks. In particular, combining information from T1Gdand T2 is interesting since they respectively provide information on Blood-Brain Barrier Disruption and oedema. Additionally, new PET tracers [116-122]may provide more information (size, shape and radiopharmaceuticalconcentration) and thus, improve significantly GBM investigation.Furthermore, spectrometry MRSI [73, 109, 123, 124] also provides important tumours characteristics. With these new features, machine-learning strategies may achieve segmentation with refining capacities and active tumour probability mapping. With suchactive tumours or relapse probability maps, treatment planning might be achieved from a realistic model including tumour cell density around the tumour core.

\section{Conflict of interest None.}

1. Maraninchi, D., N. Cerf, and P. Bousquet, Rapport sur la dynamique d'évolution des taux de mortalité des principaux cancers en France 2010, INCa - Inserm.

2. Kenneth R. Hess, K.R.B.a.M.L.B., Adult Glioma Incidence Trends in the United States, 1977-2000. Cancer, 2004. 101(10): p. 7.

3. Stupp, R., Malignant glioma: ESMO clinical recommendations for diagnosis, treatment and follow-up. Ann Oncol, 2007. 18 Suppl 2: p. ii69-70.

4. Stupp R, H.M., Mason WP, et al., Effects of radiotherapy with concomitant and adjuvant temozolomide versus radiotherapy alone on survival in glioblastoma in a randomised phase III study: 5-year analysis of the EORTC-NCIC trial. Lancet Oncol, 2009: p. 8.

5. Lacroix, M., et al., A multivariate analysis of 416 patients with glioblastoma multiforme: prognosis, extent of resection, and survival. Journal of neurosurgery, 2001. 95(2): p. 190-8.

6. Norred, S.E. and J.A. Johnson, Magnetic resonance-guided laser induced thermal therapy for glioblastoma multiforme: a review. Biomed Res Int, 2014. 2014: p. 761312.

7. Yang, F.Y., et al., Treating glioblastoma multiforme with selective high-dose liposomal doxorubicin chemotherapy induced by repeated focused ultrasound. Int J Nanomedicine, 2012. 7: p. 965-74.

8. Hingtgen, S., et al., Real-time multi-modality imaging of glioblastoma tumor resection and recurrence. J Neurooncol, 2013. 111(2): p. 153-61.

9. Johansson, A., et al., Protoporphyrin IX fluorescence and photobleaching during interstitial photodynamic therapy of malignant gliomas for early treatment prognosis. Lasers Surg Med, 2013. 45(4): p. 225-34.

10. Leroy, H.A., et al., Fluorescence guided resection and glioblastoma in 2015: A review. Lasers Surg Med, 2015. 47(5): p. 441-51.

11. Krammer, B. and K. Plaetzer, ALA and its clinical impact, from bench to bedside. Photochem Photobiol Sci, 2008. 7(3): p. 283-9.

12. Kanako S, K.M., Photodynamic medicine in malignant glioma, the reason why ALA induced PpIX is accumulated. 2008.

13. Stummer, W., et al., Technical principles for protoporphyrin-IX-fluorescence guided microsurgical resection of malignant glioma tissue. Acta neurochirurgica, 1998. 140(10): p. 995-1000.

14. Stummer, W., et al., Intraoperative detection of malignant gliomas by 5-aminolevulinic acid-induced porphyrin fluorescence. Neurosurgery, 1998. 42(3): p. 518-25; discussion 525-6.

15. Stummer, W., et al., Fluorescence-guided surgery with 5-aminolevulinic acid for resection of malignant glioma: a randomised controlled multicentre phase III trial. Lancet Oncol, 2006. 7(5): p. 392-401.

16. Jacquesson, T., et al., [Surgery of high-grade gliomas guided by fluorescence: a retrospective study of 22 patients]. Neurochirurgie, 2013. 59(1): p. 9-16.

17. Dhermain, F., Radiotherapy of high-grade gliomas: current standards and new concepts, innovations in imaging and radiotherapy, and new therapeutic approaches. Chin J Cancer, 2014. 33(1): p. 16-24.

18. Stummer, W., et al., Fluorescence-guided surgery with 5-aminolevulinic acid for resection of malignant glioma: a randomised controlled multicentre phase III trial. The lancet oncology, 2006. 7(5): p. 392401.

19. Phenix, C.P., et al., High intensity focused ultrasound technology, its scope and applications in therapy and drug delivery.J Pharm Pharm Sci, 2014. 17(1): p. 136-53. 
20. Aubry, J.F., et al., Ultrasons focalisés de forte intensité pour la thérapie transcrânienne du cerveau.IRBM, 2010. 31(2): p. 87-91.

21. Feng-Yi Yang, G.-L.L., Shih-Cheng Horng, Tien-Kuei Chang, Shih-Yen Wu, Tai-Tong Wong, and a.H.-E. Wang, Pulsed High-Intensity Focused Ultrasound Enhances the Relative Permeability of the Blood-Tumor Barrier in a Glioma-Bearing Rat Model.IEEE TRANSACTIONS ON ULTRASONICS, FERROELECTRICS, AND FREQUENCY CONTROL, 2011. 58(5): p. 7.

22. Lafon, C., et al., Développement d'un dispositif expérimental ultrasonore pour le largage ciblé et contrôlé d'une chimiothérapie encapsulée.IRBM, 2009. 30(4): p. 171-173.

23. Beck, T.J., et al., Interstitial photodynamic therapy of nonresectable malignant glioma recurrences using 5-aminolevulinic acid induced protoporphyrin IX. Lasers in Surgery and Medicine, 2007. 39(5): p. 386-93.

24. Whelan, H.T., High-grade glioma/glioblastoma multiforme: is there a role for photodynamic therapy? J Natl Compr Canc Netw, 2012. 10 Suppl 2: p. S31-4.

25. Jonathan P. Celli, B.Q.S., Imran Rizvi,Conor L. Evans, Kimberley S. Samkoe, Sarika Verma, and a.T.H. Brian W. Pogue, Imaging and Photodynamic Therapy: Mechanisms, Monitoring, and Optimization. Chemical Reviews, 2010. 110(5): p. 44.

26. Muller, P.J. and B.C. Wilson, Photodynamic therapy of brain tumors-A work in progress. Lasers in Surgery and Medicine, 2006. 38(5): p. 384-389.

27. Agostinis, P., et al., Photodynamic therapy of cancer: an update. CA Cancer J Clin, 2011. 61(4): p. 250-81.

28. Zaak, D., et al., Photodynamic Therapy by Means of 5-ALA Induced PPIX in Human Prostate CancerPreliminary Results. Medical Laser Application, 2003. 18(1): p. 91-95.

29. Betrouni, N., et al., Image-guided laser therapies for prostate cancer. IRBM, 2013. 34(1): p. 28-32.

30. Friedberg, J.S., et al., A phase I study of Foscan-mediated photodynamic therapy and surgery in patients with mesothelioma. Ann Thorac Surg, 2003. 75(3): p. 952-9.

31. Campbell, S.M., et al., Clinical investigation of the novel iron-chelating agent, CP94, to enhance topical photodynamic therapy of nodular basal cell carcinoma. Br J Dermatol, 2008. 159(2): p. 387-93.

32. Cochrane, C., et al., New design of textile light diffusers for photodynamic therapy. Mater Sci Eng C Mater Biol Appl, 2013. 33(3): p. 1170-5.

33. Johansson, A., et al., 5-Aminolevulinic Acid-induced Protoporphyrin IX Levels in Tissue of Human Malignant Brain Tumors. Photochem Photobiol, 2010.

34. Stummer, W., et al., Long-sustaining response in a patient with non-resectable, distant recurrence of glioblastoma multiforme treated by interstitial photodynamic therapy using 5-ALA: case report. J Neurooncol, 2008. 87(1): p. 103-9.

35. Ito, S., et al., Oedema formation in experimental photo-irradiation therapy of brain tumours using 5 ALA. Acta Neurochir (Wien), 2005. 147(1): p. 57-65; discussion 65.

36. Tetard, M.C., et al., Experimental use of Photodynamic Therapy in high grade gliomas: a review focused on 5-aminolevulinic acid. Photodiagnosis Photodyn Ther, 2014.

37. Benov, L., Photodynamic Therapy: Current Status and Future Directions. Med Princ Pract, 2014.

38. Hennig, G., H. Stepp, and A. Johansson, Photobleaching-based method to individualize irradiation time during interstitial 5-aminolevulinic acid photodynamic therapy. Photodiagnosis Photodyn Ther, 2011. 8(3): p. 275-81.

39. Wen, Z., et al., MR imaging of high-grade brain tumors using endogenous protein and peptide-based contrast. Neuroimage, 2010. 51(2): p. 616-22.

40. Vigneron, D., et al., Three-dimensional magnetic resonance spectroscopic imaging of histologically confirmed brain tumors. Magn Reson Imaging, 2001. 19(1): p. 89-101.

41. Lu, S., et al., Diffusion-tensor MR imaging of intracranial neoplasia and associated peritumoral edema: introduction of the tumor infiltration index. Radiology, 2004. 232(1): p. 221-8.

42. Kang, H.Y., et al., Comparison of the Effect of Vessel Size Imaging and Cerebral Blood Volume Derived from Perfusion MR Imaging on Glioma Grading. AJNR Am J Neuroradiol, 2015.

43. Barone, D.G., T.A. Lawrie, and M.G. Hart, Image guided surgery for the resection of brain tumours. Cochrane Database Syst Rev, 2014. 1: p. CD009685.

44. Shamir, R.R., et al. Trajectory planning with Augmented Reality for improved risk assessment in imageguided keyhole neurosurgery. in Biomedical Imaging: From Nano to Macro, 2011 IEEE International Symposium on. 2011.

45. Sizoo, E.M., et al., Decision-making in the end-of-life phase of high-grade glioma patients. Eur $\mathrm{J}$ Cancer, 2012. 48(2): p. 226-32.

46. Menze, B.H., et al., Image based modeling of tumor growth in patients with glioma, in Optimal control in image processing, C.S. Garbe, et al., Editors. 2011, Springer: Heidelberg / Germany. 
47. Bauer, S., et al., A survey of MRI-based medical image analysis for brain tumor studies. Phys Med Biol, 2013. 58(13): p. R97-129.

48. Gordillo, N., E. Montseny, and P. Sobrevilla, State of the art survey on MRI brain tumor segmentation. Magn Reson Imaging, 2013. 31(8): p. 1426-38.

49. Letteboer, M.M., et al., Segmentation of tumors in magnetic resonance brain images using an interactive multiscale watershed algorithm. Acad Radiol, 2004. 11(10): p. 1125-38.

50. Franz, A., S. Remmele, and J. Keupp. Brain tumour segmentation and tumour tissue classification based on multiple MR protocols. 2011.

51. Toennies, K., M. Rak, and K. Engel, Deformable part models for object detection in medical images. Biomed Eng Online, 2014. 13 Suppl 1: p. S1.

52. He, L., et al., A comparative study of deformable contour methods on medical image segmentation. Image and Vision Computing, 2008. 26(2): p. 141-163.

53. Liang, J., T. McInerney, and D. Terzopoulos, United snakes. Med Image Anal, 2006. 10(2): p. 215-33.

54. Germond, L., et al., A cooperative framework for segmentation of MRI brain scans. Artif Intell Med, 2000. 20(1): p. 77-93.

55. Adiga, P.S. and B.B. Chaudhuri, Region based techniques for segmentation of volumetric histopathological images. Comput Methods Programs Biomed, 2000. 61(1): p. 23-47.

56. Sachdeva, J., et al., A novel content-based active contour model for brain tumor segmentation. Magn Reson Imaging, 2012. 30(5): p. 694-715.

57. Popuri, K., et al., 3D variational brain tumor segmentation using Dirichlet priors on a clustered feature set. International Journal of Computer Assisted Radiology and Surgery, 2012. 7(4): p. 493-506.

58. Tangaro, S., et al., Automated voxel-by-voxel tissue classification for hippocampal segmentation: Methods and validation. Phys Med, 2014.

59. Stough, J.V., et al., Automatic method for thalamus parcellation using multi-modal feature classification. Med Image Comput Comput Assist Interv, 2014. 17(Pt 3): p. 169-76.

60. Meier, R., et al., Patient-specific semi-supervised learning for postoperative brain tumor segmentation. Med Image Comput Comput Assist Interv, 2014. 17(Pt 1): p. 714-21.

61. Dolz, J., L. Massoptier, and M. Vermandel, Segmentation algorithms of subcortical brain structures on MRI for radiotherapy and radiosurgery: A survey. IRBM, 2015.

62. Clark, M.C., et al., Automatic tumor segmentation using knowledge-based techniques. IEEE Trans Med Imaging, 1998. 17(2): p. 187-201.

63. Corso, J.J., et al., Efficient Multilevel Brain Tumor Segmentation With Integrated Bayesian Model Classification. IEEE Transactions on Medical Imaging, 2008. 27(5): p. 629-640.

64. Sharon, E.B., A., Basri, R., Segmentation and Boundary Detection Using Multiscale Intensity Measurements. Computer Vision and Pattern Recognition, 2001. CVPR 2001. Proceedings of the 2001 IEEE 2001. 1: p. 8.

65. Jiang, J., et al., 3D brain tumor segmentation in multimodal MR images based on learning populationand patient-specific feature sets. Comput Med Imaging Graph, 2013. 37(7-8): p. 512-21.

66. Cordova, J.S., et al., Quantitative tumor segmentation for evaluation of extent of glioblastoma resection to facilitate multisite clinical trials. Transl Oncol, 2014. 7(1): p. 40-7.

67. Juan-Albarracin, J., et al., Automated glioblastoma segmentation based on a multiparametric structured unsupervised classification. PLoS One, 2015. 10(5): p. e0125143.

68. Khalvati, F., et al., Automated Segmentation of Breast in 3D MR Images Using a Robust Atlas. IEEE Trans Med Imaging, 2014.

69. Ullmann, J.F., et al., Development of MRI-based atlases of non-human brains. J Comp Neurol, 2014.

70. Davatzikos, C., et al., Multi-parametric analysis and registration of brain tumors: constructing statistical atlases and diagnostic tools of predictive value. Conf Proc IEEE Eng Med Biol Soc, 2011. 2011: p. 6979-81.

71. Lecellier, F., S. Jehan-Besson, and J. Fadili, Statistical region-based active contours for segmentation: An overview. IRBM, 2014. 35(1): p. 3-10.

72. Prastawa, M., et al., A brain tumor segmentation framework based on outlier detection. Med Image Anal, 2004. 8(3): p. 275-83.

73. Luts, J., et al., Nosologic imaging of the brain: segmentation and classification using MRI and MRSI. NMR Biomed, 2009. 22(4): p. 374-90.

74. Gooya, A., et al., Joint segmentation and deformable registration of brain scans guided by a tumor growth model. Med Image Comput Comput Assist Interv, 2011. 14(Pt 2): p. 532-40.

75. Brosch, T., R. Tam, and N. Initiative for the Alzheimers Disease, Manifold learning of brain MRIs by deep learning. Med Image Comput Comput Assist Interv, 2013. 16(Pt 2): p. 633-40.

76. Bishop, C.M., Pattern Recognition and Machine Learning. 2006: Springer. 
77. Liu, R., Z. Lin, and Z. Su, Learning Markov random walks for robust subspace clustering and estimation. Neural Networks, 2014. 59(0): p. 1-15.

78. Prasad, G., et al., Skull-stripping with machine learning deformable organisms. Journal of Neuroscience Methods, 2014. 236(0): p. 114-124.

79. Wang, S. and R.M. Summers, Machine learning and radiology. Med Image Anal, 2012. 16(5): p. 93351 .

80. Iftekharuddin, K.M., et al., Fractal-based brain tumor detection in multimodal MRI. Applied Mathematics and Computation, 2009. 207(1): p. 23-41.

81. Zikic, D., B. Glocker, and A. Criminisi, Encoding atlases by randomized classification forests for efficient multi-atlas label propagation. Med Image Anal, 2014. 18(8): p. 1262-73.

82. Prior, F.W., et al., Predicting a multi-parametric probability map of active tumor extent using random forests. Conf Proc IEEE Eng Med Biol Soc, 2013. 2013: p. 6478-81.

83. Zikic, D., et al., Decision forests for tissue-specific segmentation of high-grade gliomas in multichannel MR. Med Image Comput Comput Assist Interv, 2012. 15(Pt 3): p. 369-76.

84. Menze B, J.A., Bauer S, Kalpathy-Cramer J, Farahani K, et al. (n.d.), The Multimodal Brain Tumor Image Segmentation Benchmark (BRATS). 2014.

85. Kim, S., et al., Deep learning of support vector machines with class probability output networks. Neural Networks, 2014(0).

86. Mehta, S.S. and N.S. Lingayat, SVM-based algorithm for recognition of QRS complexes in electrocardiogram. IRBM, 2008. 29(5): p. 310-317.

87. Luts, J., et al., A tutorial on support vector machine-based methods for classification problems in chemometrics. Analytica Chimica Acta, 2010. 665(2): p. 129-145.

88. Burges, C.C., A Tutorial on Support Vector Machines for Pattern Recognition. Data Mining and Knowledge Discovery, 1998. 2(2): p. 121-167.

89. $\mathrm{Wu}, \mathrm{W}$., et al., Brain tumor detection and segmentation in a CRF (conditional random fields) framework with pixel-pairwise affinity and superpixel-level features. International Journal of Computer Assisted Radiology and Surgery, 2014. 9(2): p. 241-253.

90. Ji, S., et al., A new multistage medical segmentation method based on superpixel and fuzzy clustering. Comput Math Methods Med, 2014. 2014: p. 747549.

91. Cheng, J., et al., Superpixel classification based optic cup segmentation. Med Image Comput Comput Assist Interv, 2013. 16(Pt 3): p. 421-8.

92. Parag, T., S. Plaza, and L. Scheffer, Small sample learning of superpixel classifiers for EM segmentation. Med Image Comput Comput Assist Interv, 2014. 17(Pt 1): p. 389-97.

93. Porz, N., et al., Multi-modal glioblastoma segmentation: man versus machine. PLoS One, 2014. 9(5): p. e96873.

94. Rios Velazquez, E., et al., Fully automatic GBM segmentation in the TCGA-GBM dataset: Prognosis and correlation with VASARI features. Scientific Reports, 2015. 5: p. 16822.

95. Unkelbach, J., et al., Radiotherapy planning for glioblastoma based on a tumor growth model: implications for spatial dose redistribution. Phys Med Biol, 2014. 59(3): p. 771-89.

96. Unkelbach, J., et al., Radiotherapy planning for glioblastoma based on a tumor growth model: improving target volume delineation. Phys Med Biol, 2014. 59(3): p. 747-70.

97. Menze, B.H., et al., A generative model for brain tumor segmentation in multi-modal images. Med Image Comput Comput Assist Interv, 2010. 13(Pt 2): p. 151-9.

98. Hamamci, A., et al., Tumor-Cut: segmentation of brain tumors on contrast enhanced MR images for radiosurgery applications. IEEE Trans Med Imaging, 2012. 31(3): p. 790-804.

99. Prastawa, M., E. Bullitt, and G. Gerig, Synthetic Ground Truth for Validation of Brain Tumor MRI Segmentation. Medical image computing and computer-assisted intervention : MICCAI ... International Conference on Medical Image Computing and Computer-Assisted Intervention, 2005. 8(Pt 1): p. 26-33.

100. Archip, N., F.A. Jolesz, and S.K. Warfield, A Validation Framework for Brain Tumor Segmentation. Academic Radiology, 2007. 14(10): p. 1242-1251.

101. Ellis, H.P., et al., Current Challenges in Glioblastoma: Intratumour Heterogeneity, Residual Disease, and Models to Predict Disease Recurrence. Front Oncol, 2015. 5: p. 251.

102. Guyon, I., et al., Gene Selection for Cancer Classification using Support Vector Machines. Machine Learning, 2002. 46(1-3): p. 389-422.

103. Jain, R., et al., Genomic mapping and survival prediction in glioblastoma: molecular subclassification strengthened by hemodynamic imaging biomarkers. Radiology, 2013. 267(1): p. 212-20.

104. Gutman, D.A., et al., MR imaging predictors of molecular profile and survival: multi-institutional study of the TCGA glioblastoma data set. Radiology, 2013. 267(2): p. 560-9.

105. Gevaert, O., et al., Glioblastoma multiforme: exploratory radiogenomic analysis by using quantitative image features. Radiology, 2014. 273(1): p. 168-74. 
106. Zinn, P.O., et al., Radiogenomic mapping of edema/cellular invasion MRI-phenotypes in glioblastoma multiforme. PLoS One, 2011. 6(10): p. e25451.

107. Taman Upadhaya, Y.M., Eric Stindel, Pierre-Jean Le Reste, Mathieu Hatt, Prognostic value of multimodal mri tumor features in glioblastoma multiforme using textural features analysis, in ISBI 2015. 2015: Brooklyn, NY, USA. p. 5.

108. Frieboes, H.B., et al., An integrated computational/experimental model of tumor invasion. Cancer Res, 2006. 66(3): p. 1597-604.

109. Schreibmann, E., et al., TH-CD-204-03: A Glioblastoma Tumor Growth Prediction Model Using Volumetric MR Spectroscopic Imaging for Radiation Therapy Response. Med Phys, 2015. 42(6): p. 3732.

110. Mazurowski, M.A., et al., Computer-extracted MR imaging features are associated with survival in glioblastoma patients. J Neurooncol, 2014. 120(3): p. 483-8.

111. Harris, R.J., et al., 18F-FDOPA and 18F-FLT positron emission tomography parametric response maps predict response in recurrent malignant gliomas treated with bevacizumab. Neuro Oncol, 2012. 14(8): p. 1079-89.

112. Pyka, T., et al., Prediction of glioma recurrence using dynamic (1)(8)F-fluoroethyltyrosine PET. AJNR Am J Neuroradiol, 2014. 35(10): p. 1924-9.

113. Bosnyak, E., et al., Tryptophan PET predicts spatial and temporal patterns of post-treatment glioblastoma progression detected by contrast-enhanced MRI. J Neurooncol, 2015.

114. Corroyer-Dulmont, A., et al., Multimodal imaging based on MRI and PET reveals [F]FLT PET as a specific and early indicator of treatment efficacy in a preclinical model of recurrent glioblastoma. Eur $\mathbf{J}$ Nucl Med Mol Imaging, 2015.

115. Corso, J.J., et al., Efficient multilevel brain tumor segmentation with integrated bayesian model classification. IEEE Trans Med Imaging, 2008. 27(5): p. 629-40.

116. Niyazi, M., et al., FET-PET for malignant glioma treatment planning. Radiother Oncol, 2011. 99(1): p. 44-8.

117. Walter, F., et al., Technical Issues of [(18)F]FET-PET Imaging for Radiation Therapy Planning in Malignant Glioma Patients - A Review. Front Oncol, 2012. 2: p. 130.

118. Pyka, T., et al., Textural analysis of pre-therapeutic [18F]-FET-PET and its correlation with tumor grade and patient survival in high-grade gliomas. Eur J Nucl Med Mol Imaging, 2015.

119. Bell, C., et al., Increasing feasibility and utility of F-FDOPA PET for the management of glioma. Nucl Med Biol, 2015.

120. Fueger, B.J., et al., Correlation of 6-18F-fluoro-L-dopa PET uptake with proliferation and tumor grade in newly diagnosed and recurrent gliomas. J Nucl Med, 2010. 51(10): p. 1532-8.

121. Walter, F., et al., Impact of 3,4-dihydroxy-6-18F-fluoro-L-phenylalanine PET/CT on managing patients with brain tumors: the referring physician's perspective. J Nucl Med, 2012. 53(3): p. 393-8.

122. Pafundi, D.H., et al., Biopsy validation of 18F-DOPA PET and biodistribution in gliomas for neurosurgical planning and radiotherapy target delineation: results of a prospective pilot study. Neuro Oncol, 2013. 15(8): p. 1058-67.

123. Nachimuthu, D.S. and A. Baladhandapani, Multidimensional Texture Characterization: On Analysis for Brain Tumor Tissues Using MRS and MRI. J Digit Imaging, 2014.

124. Ranjith, G., et al., Machine learning methods for the classification of gliomas: Initial results using features extracted from MR spectroscopy. Neuroradiol J, 2015. 28(2): p. 106-11. 